\title{
The Effect of Stressful Life Events on Postpartum Depression: Findings from the 2009-2011 Mississippi Pregnancy Risk Assessment Monitoring System
}

\author{
Mina Qobadi ${ }^{1}$ - Charlene Collier ${ }^{1,2} \cdot$ Lei $^{\text {Zhang }}{ }^{1}$
}

Published online: 23 June 2016

(c) Springer Science+Business Media New York 2016

\begin{abstract}
Objectives To determine the prevalence of postpartum depression (PPD) among new mothers in Mississippi during 2009-2011 and evaluate the effects of different stressful life events in the year before delivery on the likelihood of PPD. Methods We used Mississippi Pregnancy Risk Assessment Monitoring System (PRAMS) 2009-2011 data $(n=3695)$ to evaluate the effects of different stressful life events on PPD. We categorized 13 stressors into 4 groups: financial, relational, trauma-related, and emotional. A composite score of the mothers' responses $(\geq 10)$ to the three items: "I felt down, depressed, or sad", "I felt hopeless", and "I felt slowed down" was used to measure PPD. The items were rated on a Likert scale from (1) never to 5 (always). Descriptive statistics, Chi square tests, $t$ tests, and logistic regression analyses were conducted using SAS 9.3 Proc Survey procedure (SAS Institute, Cary, NC, USA). Results The overall prevalence of self-reported PPD was $14.8 \%$. Mothers who experienced high relational with low financial and high trauma related stresses had the highest likelihood of PPD diagnosis after adjusting for confounders $(\mathrm{OR}=8.6$; $95 \%$
\end{abstract}

Electronic supplementary material The online version of this article (doi:10.1007/s10995-016-2028-7) contains supplementary material, which is available to authorized users.

Mina Qobadi

mina.qobadi@msdh.ms.gov

Charlene Collier

Charlene.Collier@msdh.ms.gov

Lei Zhang

Lei.Zhang@msdh.ms.gov

1 Mississippi State Department of Health, 570 East Woodrow Wilson, Osborne 200, Jackson, MS 39215-1700, USA

2 University of Mississippi Medical Center, Jackson, MS, USA
CI, 3.5-21.3), followed by those who reported high relational stress with low financial and low trauma stresses $(\mathrm{OR}=5.9 ; 95 \% \mathrm{CI}, 3.5-10.2)$. Those with high financial, low relational, and low trauma had the least likelihood of PPD $(\mathrm{OR}=2.2 ; 95 \% \mathrm{CI}, 1.6-3.0)$ compared to women with low stress in all three categories. Conclusion Our findings showed that the likelihood of PPD was higher among women who had high relational stress, indicating that efforts to effectively prevent PPD need to focus on healthy relationships between partners during pregnancy.

Keywords Postpartum depression - Life events stressors · Relational stress · Prenatal screening · PRAMS

\section{Significance}

PPD is a serious mental health problem that is associated with adverse maternal and infant health outcomes. Although previous studies suggested that stressful life events increase the risk of PPD, the existing literature lacks in-depth information on effects of different types of stressors on PPD and their interactions. Identifying the relationship between different types of stress and PPD in new mothers is critical to developing strategies to reduce PPD rates among new mothers.

\section{Introduction}

Pregnancy can be a stressful time for many expecting mothers. Some women can further experience acute highly stressful events during pregnancy, such as the loss of a job or the death of a loved one. Some women may live with chronic levels of high stress related to 
relationships or financial strain, all of which may contribute to the development of postpartum depression (PPD). PPD is a serious mental health condition that affects up to $13 \%$ of new mothers, occurring within the first 4 weeks and up to 1 year after delivery [12]. Evidence has shown that both stressful life events and PPD can negatively impact maternal and infant health $[14,20,21,24]$. Mothers with PPD are less likely to breastfeed their infants, get preventive health services, use desirable safe infant sleep practices, and follow safety recommendations like using a car seat or smoking alarm [11]. Furthermore, PPD has adverse effects on maternal interactions and mother-infant bonding. Mother-infant relationships play an important role in infants' social, cognitive and behavioral development; depressed mothers are less responsive to their infants, show less attachment and attunement, and may demonstrate disrupted parenting behaviors, which may contribute to poor infant health outcomes [5, 29].

Previous studies suggest that stressful life events during pregnancy increase the risk of PPD [7, 9, 26, 27]. Researchers generally employ three approaches in determining the relationship between stressful life events and PPD. First, some studies examine the risk of individual stressors on PPD [18]. However, correlation among stressors is not considered using this approach and the strength of the relationship between individual stressors and PPD may be overestimated [19]. Some researchers use a cumulative approach, regardless of types of stressors, and report that the accumulation of reported life stressors increases the risk of PPD [4, 28]. This approach does not consider the unique effect of each stressor on PPD [19]. Other studies categorize life event stressors in four domains including financial, relational, trauma, and emotional and evaluate the effects of these domains on PPD, regardless of the number of stressors in each category $[6,16]$. These approaches may neglect co-occurrence of different stress domains. Unlike the previous studies, Liu and Tronick [19] developed an approach that integrates both accumulation of life stressors and their specific role in PPD. These authors examined the risk level of each stress domain and the different risk combinations, rather than simple summation of prenatal stressors regardless of stressor type and/or grouping prenatal life stressors regardless of number of stressors in each group. In this study, we used Liu's integrated approach to capture the risk level of each domain of stressors and to evaluate how varying combinations and levels of stress domains impact PPD. We sought to determine the prevalence of PPD among new mothers in Mississippi during 2009-2011 and evaluate the effects of different stressful life events in the year before delivery on the likelihood of PPD.

\section{Methods}

\section{Study Design and Participants}

We used Mississippi Pregnancy Risk Assessment Monitoring System (PRAMS) data from 2009 to 2011 $(\mathrm{n}=3836)$ to evaluate the association of different stressful life events with PPD. PRAMS is an on-going national surveillance system designed to identify and monitor maternal behaviors and experiences before, during and after pregnancy among women delivering a live birth. The PRAMS questionnaire includes core questions that are asked by all participating states as well as state-specific questions that are chosen or developed by individual states to supplement the core questions. Each month, approximately 250 new mothers are randomly selected from birth certificates to participate in the self-administered mail-in questionnaire. Mothers who do not complete the questionnaires are followed up with a standardized telephone interview. Informed consent is obtained from all participants. In Mississippi the sample is stratified by birth weight: women with very low birth weight $(<1500 \mathrm{~g})$ or low birth weight (1500-2499 g) infants are sampled at a higher rate. For this analysis, records were excluded from the sample if the mother was a non-resident, the mother gave birth out of state, there was missing data from birth certificates, or there were delayed processing of the birth certificates. The 2009-2011 Mississippi PRAMS questionnaires were approved by the Institutional Review Boards of the Centers for Disease Control and Prevention (CDC) and the Mississippi State Department of Health. The study was approved by the Institutional Review Board at the Mississippi State Department of Health.

Response rates for the 2009, 2010 and 2011 Mississippi PRAMS datasets were 69.7, 64.4, and $64.0 \%$ respectively. The threshold response rate for a survey to be representative recommended by the CDC is $65.0 \%$. Of 3836 respondents, 141 mothers with missing data on PPD $(\mathrm{n}=80)$ or stressful life events $(\mathrm{n}=61)$ were excluded from the analysis.

\section{Measures}

\section{Assessment of Postpartum Depression}

The study definition for PPD was based on the mother's opinion of her mood status. In the 2009- 2011 Mississippi PRAMS core questionnaire, mothers were asked to describe their feelings since their new baby was born on a Likert scale with never $=1$, rarely $=2$, sometimes $=3$, often $=4$, and always $=5$ for these three items (Appendix 1 in Supplementary Material): 
a. I felt down, depressed or sad

b. I felt hopeless

c. I felt slowed down.

As recommended by the $\mathrm{CDC}$, we summed the scores of the mothers' responses to these above items and defined mothers as experiencing PPD if their composite score was $\geq 10$ [16].

\section{Stressful Life Events}

Stressful life events were measured using 13 core questions from the PRAMS questionnaire that assess various social stressors for a pregnant mother (Appendix 1 in Supplementary Material). The questionnaire asks the mothers if they experienced any of the 13 events in the 12 months before they delivered their baby. The events are listed as: (1) A close family member was very sick and had to go into the hospital, (2) I got separated or divorced from my husband or partner, (3) I moved to a new address, (4) I was homeless, (5) My husband or partner lost his job, (6) I lost my job even though I wanted to go on working, (7) I argued with my husband or partner more than usual, (8) My husband or partner said he did not want me to be pregnant, (9) I had a lot of bills I couldn't pay, (10) I was in a physical fight, (11) My husband or partner or I went to jail, (12) someone very close to me had a problem with drinking or drugs, and (13) someone very close to me died [6]. Based on previous studies [1, 6, 16], we grouped the 13 stressful life events into four categories: financial (unable to pay bills, moved to a new address, lost job, or husband/partner lost job), relational (argued more than usual with partner/husband, separated/divorced or husband/partner did not want pregnancy), trauma-related (homeless, had a physical fight, husband/partner or I went to jail, or someone very close had drinking or drugs problem), and emotional (family member was ill and hospitalized or someone very close died). Mothers reporting one or more stressful life events in a stress category qualified for inclusion in that category.

\section{Statistical Analyses}

To account for the stratified and weighted sample, we analyzed data using the survey procedures in SAS 9.3 (SAS Institute, Inc, Cary, North Carolina). Descriptive statistics were used to summarize baseline sample characteristics by PPD. Maternal characteristics in this study were race (white and black), age ( $<20,20-24,25-29, \geq 30$ years), annual household income $(<\$ 10,000, \$ 10,000-\$ 19,999$, $\$ 20,000-\$ 34,999, \geq \$ 35,000)$, education ( $<$ High School, High School, College, Graduate School), marital status
(Married and Other) and parity ( $0,1, \geq 2$ births). All proportions represent weighted percentages generalized to Mississippi women.

As mentioned above, we grouped the 13 stressful life events into the four categories: financial, relational, trauma-related, and emotional. Then, a sum of the item responses within each category was calculated. In order to examine both specific life stressors and a cumulative count as a risk factor for PPD, we created an integrated variable reflecting both the severity level of exposures and the specific nature of stressors by using Liu and Tronick's approach. Based on their approach, each category was considered low level if it included $<2$ stressors, and high level if its stressor count was $\geq 2$. Three logistic regression models were developed to provide an estimate of associations between PPD, stressful life events, maternal characteristics, and the interaction between these variables. Although the odds ratio is prone to overestimate the magnitude of the association between the outcome and exposure when the outcome of interest is common $(>20 \%)$ [13], for retrospective studies with binary outcomes that require adjustment for covariates and interaction estimations, the odds ratio is preferred because it has desirable mathematical properties and will not be misleading when interpreted correctly [25]. For model I, we measured unadjusted effects of each category of stressors and maternal characteristics and the likelihood of PPD. In model II, we measured the independent effects of each category after controlling for all other categories of stressors and maternal characteristics. Variables were included in the multivariable logistic regression model if their $p$ value was $<0.20$ on bivariate analysis. Given the cooccurrence of the stressors and the potential associations of socio-demographic factors with each other, we tested interactions between the stressors, as well as interactions between socio-demographic variables, and added significant interaction terms into our final model (model III).

\section{Results}

The participants' characteristics are presented in Table 1. The respondents were predominantly unmarried, 20-24 years old, first time mothers, with high school education and with $<\$ 10,000$ annual household income, and had financial stress. The majority of respondents were white $(54 \%)$, with an almost equal percentage of black women (45\%), similar to the Mississippi general population. The most common stressful life events reported during pregnancy included: moving to a new address (32\%), arguing a lot with partner/husband (27.9\%), illness of someone very close $(27.2 \%)$, having trouble paying bills (23\%), and having someone very close die $(21.2 \%)$. The 
Table 1 Characteristics of Mississippi PRAMS 2009-2011 participants, and prevalence of PPD

\begin{tabular}{|c|c|c|c|c|c|}
\hline \multirow[t]{2}{*}{ Characteristics } & \multicolumn{2}{|c|}{ Total $(n=3695)$} & \multicolumn{2}{|c|}{ With PPD $(n=647)$} & \multirow[t]{2}{*}{$p$ value } \\
\hline & $\mathrm{N}$ & Weighted \% & $\mathrm{N}$ & Weighted \% & \\
\hline Race & & & & & 0.21 \\
\hline White & 1672 & 54.1 & 314 & 15.7 & \\
\hline Black & 1964 & 45.9 & 324 & 13.8 & \\
\hline Education & & & & & $<0.001$ \\
\hline$<$ High school & 107 & 2.3 & 27 & 15.8 & \\
\hline High school & 1860 & 48.9 & 348 & 16.4 & \\
\hline College & 1053 & 28.3 & 200 & 16.7 & \\
\hline$>$ College & 668 & 20.0 & 71 & 8.3 & \\
\hline Age (years) & & & & & $<0.001$ \\
\hline$<20$ & 653 & 15.3 & 133 & 20.6 & \\
\hline $20-24$ & 1206 & 33.9 & 225 & 16.6 & \\
\hline $25-29$ & 949 & 27.9 & 154 & 11.9 & \\
\hline$\geq 30$ & 857 & 22.9 & 135 & 11.9 & \\
\hline Annual household income & & & & & $<0.0001$ \\
\hline$<\$ 10,000$ & 1160 & 31.5 & 292 & 22.9 & \\
\hline$\$ 10,000-\$ 19,999$ & 811 & 23.2 & 140 & 15.6 & \\
\hline$\$ 20,000-\$ 34,999$ & 636 & 19.0 & 96 & 12.2 & \\
\hline$\geq \$ 35,000$ & 776 & 26.4 & 95 & 9.0 & \\
\hline Marital status & & & & & 0.01 \\
\hline Married & 1452 & 43.8 & 232 & 12.6 & \\
\hline Unmarried & 2243 & 56.2 & 415 & 16.6 & \\
\hline Parity & & & & & 0.28 \\
\hline 0 births & 1395 & 36.3 & 231 & 15.8 & \\
\hline 1 birth & 1026 & 32.3 & 160 & 13.0 & \\
\hline$\geq 2$ births & 1274 & 33.4 & 256 & 15.4 & \\
\hline Any stressful life events & & & & & $<0.0001$ \\
\hline Yes & 2689 & 71.9 & 583 & 18.9 & \\
\hline No & 1006 & 28.1 & 64 & 4.3 & \\
\hline Financial stress & 1896 & 51.3 & 446 & 20.5 & $<0.0001$ \\
\hline Husband/partner lost job & 502 & 14.7 & 146 & 27.8 & \\
\hline Trouble paying bill & 896 & 23.0 & 279 & 27.5 & \\
\hline Mother lost job & 471 & 12.2 & 130 & 25.0 & \\
\hline Mother moved & 1159 & 32.3 & 242 & 17.4 & \\
\hline Relational stress & 1325 & 33.2 & 419 & 29.7 & $<0.0001$ \\
\hline Husband/partner did not want pregnancy & 339 & 8.0 & 121 & 34.8 & \\
\hline Argued a lot & 1128 & 27.9 & 384 & 32.1 & \\
\hline Separation or Divorce & 395 & 9.6 & 118 & 28.5 & \\
\hline Trauma-related stress & 742 & 19.4 & 249 & 32.3 & $<0.0001$ \\
\hline Husband/partner in jail & 223 & 5.1 & 71 & 32.5 & \\
\hline Physical fight & 234 & 5.7 & 90 & 36.2 & \\
\hline Homeless & 93 & 2.2 & 37 & 39.7 & \\
\hline Drug/drinking problems of someone very close & 509 & 13.7 & 171 & 33.1 & \\
\hline Emotional stress & 1356 & 36.3 & 297 & 19.2 & 0.03 \\
\hline Illness of someone very close & 1025 & 27.2 & 230 & 20.3 & \\
\hline Death of someone very close & 797 & 21.2 & 177 & 17.6 & \\
\hline Stressful life events (Cumulative) & & & & & $<0.0001$ \\
\hline 0 & 1006 & 28.1 & 64 & 4.4 & \\
\hline $1-3$ & 1929 & 52.2 & 311 & 13.5 & \\
\hline
\end{tabular}


Table 1 continued

\begin{tabular}{lllllll}
\hline Characteristics & \multicolumn{2}{l}{ Total $(\mathrm{n}=3695)$} & & \multicolumn{2}{l}{ With PPD $(\mathrm{n}=647)$} & $p$ value \\
\cline { 2 - 3 } & $\mathrm{N}$ & Weighted $\%$ & & $\mathrm{~N}$ & Weighted $\%$ & \\
\hline $4-5$ & 466 & 12.6 & & 151 & 27.7 \\
$>5$ & 294 & 7.1 & & 121 & 43.4 \\
\hline
\end{tabular}

majority of mothers reported 1-3 stressful life events during pregnancy $(52.2 \%)$, and $28.1 \%$ of mothers reported no stress.

The prevalence of self-reported PPD was $14.8 \%$. Our findings (Table 1) show that prevalence of PPD is significantly higher among teen mothers $(20.6 \%, p<0.001)$, unmarried mothers $(16.6 \%, \mathrm{p}=0.01)$, and those with incomes $<\$ 10,000$ (22.9\%, $p<0.0001)$, and is significantly lower among mothers with a graduate degree $(8.3 \%$, $p<0.001)$. There was no significant difference in PPD between white $(15.7 \%)$ and black $(13.8 \%)$ mothers $(p=0.21)$. Also, the prevalence of PPD did not differ significantly by parity $(p=0.28)$. PPD was significantly higher in mothers who reported any stressful life events (18.9\%) compared to those who reported no stressful life events $(4.3 \%)(p<0.0001)$. Furthermore, results demonstrated a clear dose-response relationship between cumulative stress exposure and PPD prevalence. The prevalence of PPD significantly increased from the lowest cumulative stress exposure class to the highest. Mothers who reported more than 5 stressful life events had the highest prevalence of PPD $(43.4 \%, p<0.0001)$. The average number of stressful life events was significantly higher among mothers with PPD (3.5) than those without PPD (1.8) ( $p<0.0001$; data not shown).

Using bivariate and multiple logistic regression models, unadjusted and adjusted odds ratios (ORs) for the associations between stressful life events and PPD are presented in Table 2. Model I (unadjusted model) shows that mothers with high relational stress $(\mathrm{OR}=4.3 ; 95 \% \mathrm{CI}, 3.2-5.7)$ had the greatest likelihood of reporting PPD followed by mothers with high trauma-related stress $(\mathrm{OR}=4.1 ; 95 \%$ CI, 2.8-6.1), high financial stress $(\mathrm{OR}=2.6 ; 95 \% \mathrm{CI}$, 2.0-3.3), and high emotional stress $(\mathrm{OR}=1.4 ; 95 \% \mathrm{CI}$, $1.0-1.9)$. Among maternal characteristics, race and parity were not significantly associated with PPD; therefore, we excluded them from the subsequent models. In our main effect models (i.e., model II), higher levels of relational, financial and trauma related stress were associated with reported PPD. A high level of relational stress was most strongly associated with $\mathrm{PPD}(\mathrm{OR}=2.7 ; 95 \% \mathrm{CI}$, 1.8-3.9) after adjustment for other stressors. On the other hand, there was not a significant association between emotional stress and PPD after controlling for maternal characteristics and other stressors.
Table 3 shows our final model with interaction terms (model III). The best fitting model was the model including a two-way interaction term between age and marital status and a three-way interaction between financial, relational and trauma related stressors. There was no identified association between high emotional stress and PPD $(p=0.6)$, and it was therefore not included in the model. As expected, mothers with low levels of all forms of stress had the lowest prevalence of PPD (9.6\%) and served as the reference group. Compared to mothers with low financial, low relational, and low trauma-related stress, mothers who experienced high relational and high trauma- related stress but low financial stress had the greatest likelihood of PPD $(\mathrm{OR}=8.6 ; 95 \% \mathrm{CI}, 3.5-21.3)$, and those with high financial stress along with low relational, and low traumarelated stress had the least likelihood of PPD after adjusting for confounders $(\mathrm{OR}=2.2 ; 95 \% \mathrm{CI}, 1.6-3.0)$.

Furthermore, the findings showed that married teens had a greater likelihood of PPD (OR $=2.2 ; 95 \%$ CI, 1.6-3.0) compared to married mothers $\geq 30$ years old. However, unmarried older mothers had the least likelihood of PPD $(\mathrm{OR}=0.5 ; 95 \% \mathrm{CI}, 0.3-0.9)$. Being low income was independently associated with PPD after controlling for confounders. Mothers with annual household income $<\$ 10,000$ had a greater likelihood of reporting PPD symptoms $(\mathrm{OR}=2.0 ; 95 \% \mathrm{CI}, 1.3-3.2)$ compared to those with annual household income $\geq \$ 35,000$. There was not a significant relationship between education and PPD after controlling for confounders.

\section{Discussion}

In this population-based study representative of Mississippi mothers who gave birth to a live born infant during 2009-2011, we found the most common sources of stress during pregnancy to be financial stress followed by emotional and relational stress; trauma-related stress was reported the least, consistent with Banker and LaCoursiere [3]. The prevalence of PPD in this study $(14.0 \%)$ was consistent with nationally reported estimates [16]. The prevalence of PPD was highest in mothers who reported trauma-related stressors followed by relational, financial and emotional stressors, respectively. 
Table 2 Association between stressful life events, maternal characteristics and PPD: main effect models

\begin{tabular}{|c|c|c|c|}
\hline & $\mathrm{N}$ (weighted \%) & 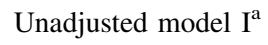 & Adjusted model $\mathrm{II}^{\mathrm{b}}$ \\
\hline \multicolumn{4}{|l|}{ Relational stressors } \\
\hline High relational stress & $422(9.6)$ & $4.3(3.2-5.7)$ & $2.7(1.8-3.9)$ \\
\hline Low relational stress & $3273(90.4)$ & (ref) & (ref) \\
\hline \multicolumn{4}{|l|}{ Financial stressors } \\
\hline High financial stress & $788(19.8)$ & $2.6(2.0-3.3)$ & $1.6(1.2-2.2)$ \\
\hline Low financial stress & $2907(78.5)$ & (ref) & (ref) \\
\hline \multicolumn{4}{|l|}{ Traumatic stressors } \\
\hline High traumatic stress & $222(5.4)$ & $4.1(2.8-6.1)$ & $2.2(1.4-3.4)$ \\
\hline Low traumatic stress & 3473 (94.6) & (ref) & (ref) \\
\hline \multicolumn{4}{|l|}{ Emotional stressors } \\
\hline High emotional stress & $466(12.0)$ & $1.4(1.0-1.9)$ & $1.1(0.8-1.5)$ \\
\hline Low emotional stress & $3229(88.0)$ & (ref) & (ref) \\
\hline \multicolumn{4}{|l|}{ Marital status } \\
\hline Unmarried & $2243(56.2)$ & $1.4(1.1-1.7)$ & $0.7(0.5-0.9)$ \\
\hline Married & $1452(43.8)$ & (ref) & (ref) \\
\hline \multicolumn{4}{|l|}{ Age (years) } \\
\hline$<20$ & $653(15.3)$ & $1.9(1.3-2.8)$ & $1.8(1.2-2.8)$ \\
\hline $20-24$ & $1206(33.9)$ & $1.5(1.1-2.0)$ & $1.1(0.8-1.6)$ \\
\hline $25-29$ & $949(27.9)$ & $1.0(0.7-1.4)$ & $0.9(0.6-1.3)$ \\
\hline$\geq 30$ & 857 (22.9) & (ref) & (ref) \\
\hline \multicolumn{4}{|l|}{ Education } \\
\hline$<$ high school & $107(2.3)$ & $2.1(1.0-4.2)$ & $1.4(0.6-3.1)$ \\
\hline High school & $1860(48.9)$ & $2.2(1.5-3.2)$ & $1.3(0.8-2.0)$ \\
\hline College & $1053(28.3)$ & $2.2(1.5-3.3)$ & $1.7(1.1-2.7)$ \\
\hline$\geq$ College & $668(20.0)$ & (ref) & (ref) \\
\hline \multicolumn{4}{|l|}{ Income } \\
\hline$<\$ 10,000$ & $1160(31.5)$ & $3.0(2.1-4.2)$ & $2.1(1.3-3.3)$ \\
\hline$\$ 10,000-\$ 19,999$ & $811(23.2)$ & $1.9(1.3-2.7)$ & $1.4(0.9-2.1)$ \\
\hline$\$ 20,000-\$ 34,999$ & $636(19.0)$ & $1.4(0.9-2.1)$ & $1.1(0.7-1.8)$ \\
\hline$\geq \$ 35,000$ & $776(26.4)$ & (ref) & (ref) \\
\hline \multicolumn{4}{|l|}{ Race } \\
\hline White & $1672(54.1)$ & $1.2(0.9-1.5)$ & - \\
\hline Black & 1964 (45.9) & (ref) & \\
\hline \multicolumn{4}{|l|}{ Parity } \\
\hline 0 & 1395 & $1.0(0.8-1.3)$ & - \\
\hline 1 & 1026 & $0.8(0.6-1.1)$ & \\
\hline$\geq 2$ & 1274 & (ref) & \\
\hline
\end{tabular}

${ }^{a}$ Unadjusted model

b Adjusted for demographic variables and others stressors excluding race and parity
Among maternal characteristics, younger age $(<20$ years old), low income $(<\$ 10,000)$ and marital status (being married) were independently associated with an increased likelihood of PPD after controlling for confounders. According to our findings, married teenage mothers had a greater likelihood of reporting PPD than adult married mothers. Married teens are known to have less stable marriages and higher rates of divorce compared to older mothers [8, 17]. Furthermore, young fathers' contribution to prenatal care and parenting is less than that of adult fathers and young fathers typically have less supportive relationships with their spouses. Compared with adult fathers, teenage fathers are more likely to come from disadvantaged family backgrounds, have lower education and income, making marriage and parenthood potentially more challenging [22].

Similar to other studies, we found a dose-response relationship between stressful life events and the 
Table 3 Association between Stressful life events, maternal characteristics and PPD: interaction effect models

\begin{tabular}{|c|c|c|c|}
\hline & $\mathrm{N}$ (weighted \%) & \%with PPD & Model III ${ }^{\mathrm{a}}$ \\
\hline \multicolumn{4}{|l|}{ Interaction terms } \\
\hline \multicolumn{4}{|l|}{ Relational $\times$ financial $\times$ trauma } \\
\hline High relational/low financial/high trauma & $35(1.0)$ & 52.8 & $8.6(3.5-21.3)$ \\
\hline High relational/low financial/low trauma & $169(3.5)$ & 41.1 & $5.9(3.5-10.2)$ \\
\hline Low relational/high financial/high trauma & $53(1.5)$ & 43.8 & $5.8(2.8-12.2)$ \\
\hline Low relational/low financial/high trauma & $57(1.5)$ & 35.2 & $4.6(2.1-10.2)$ \\
\hline High relational/high financial/high trauma & $77(1.7)$ & 33.4 & $4.3(2.1-8.7)$ \\
\hline High relational/high financial/low trauma & 141(3.7) & 33.7 & $4.1(2.4-6.9)$ \\
\hline Low relational/high financial/low trauma & $517(14.5)$ & 21.1 & $2.2(1.6-3.0)$ \\
\hline Low relational/low financial/low trauma & $2646(72.8)$ & 9.6 & (ref) \\
\hline \multicolumn{4}{|l|}{ Age $\times$ marital status } \\
\hline Married $<20$ & $56(1.7)$ & 30.1 & $2.8(1.1-7.2)$ \\
\hline Unmarried $<20$ & $597(13.6)$ & 19.4 & $1.0(0.6-1.7)$ \\
\hline Married 20-24 years old & $337(10.5)$ & 16.6 & $1.0(0.6-1.7)$ \\
\hline Unmarried 20-24 years old & $869(23.3)$ & 16.6 & $0.7(0.4-1.1)$ \\
\hline Married 25-29 years old & $514(15.9)$ & 8.6 & $0.6(0.4-1.0)$ \\
\hline Unmarried 25-29 years old & $465(12.1)$ & 16.3 & $0.7(0.4-1.2)$ \\
\hline Unmarried $\geq 30$ years old & $312(7.2)$ & 12.1 & $0.5(0.3-0.9)$ \\
\hline$\geq 30$ and married & $545(15.7)$ & 11.4 & (ref) \\
\hline \multicolumn{4}{|l|}{ Main effects } \\
\hline \multicolumn{4}{|l|}{ Emotional stress } \\
\hline High emotional stress & $466(12.0)$ & 18.9 & $1.1(0.8-1.5)$ \\
\hline Low emotional stress & $3229(88.0)$ & 14.3 & (ref) \\
\hline \multicolumn{4}{|l|}{ Education } \\
\hline$<$ High school & $107(2.3)$ & 15.8 & $1.3(0.6-3.0)$ \\
\hline High school & $1860(48.9)$ & 16.4 & $1.2(0.8-2.0)$ \\
\hline College & $1053(28.3)$ & 16.7 & $1.6(1.0-2.5)$ \\
\hline$\geq$ College & $668(20.0)$ & 8.3 & (ref) \\
\hline \multicolumn{4}{|l|}{ Annual income } \\
\hline$<\$ 10,000$ & $1160(31.5)$ & 22.9 & $2.0(1.3-3.2)$ \\
\hline$\$ 10,000-\$ 19,999$ & 811(23.2) & 15.6 & $1.3(0.8-2.1)$ \\
\hline$\$ 20,000-\$ 34,999$ & $636(19.0)$ & 12.2 & $1.0(0.6-1.6)$ \\
\hline$\geq \$ 35,000$ & $776(26.4)$ & 9.0 & (ref) \\
\hline
\end{tabular}

${ }^{a}$ Adjusted model including all covariates and interaction terms prevalence of PPD. Other studies have also found that the more stressful life events that occur in the perinatal period, the more likely mothers will experience PPD symptoms $[16,19]$. Cumulative stressors may reduce mothers' coping resources and increase the likelihood of depression.

In multivariable logistic regression without interaction terms, high relational, high trauma-related, and high financial stress were associated with PPD after adjusting for confounders. Similar to prior studies, we also found high relational stress to be the strongest predictor of PPD after adjusting for confounders [3, 16]; Yim et al. [32]. There is strong evidence that lack of perceived support from a husband or partner during pregnancy plays an important role in the occurrence and severity of PPD [30].
Adequate support can reduce the harmful effect of other stressors, allowing for better emotional responses and coping with negative events thus potentially preventing some cases of PPD and reducing the severity of symptoms among women already diagnosed with PPD [15].

In this study, we evaluated the relationship between PPD, stressful life events, and maternal characteristics. In the multivariable regression model with interaction terms presented in Table 3, we found that although mothers with low relational, financial, and trauma-related stress had the lowest prevalence of PPD, mothers with low relational and trauma-related stress but high financial stress had a much lower prevalence of PPD (21.1\%) than those with low financial stress but high relational and high trauma-related 
stress $(52.8 \%)$. These findings are not consistent with the findings from Liu and Tronick's [19] study, which found high financial stress as the strongest predictor of PPD. This could be in part explained by differences in perceived financial stress due to different economic and social contexts in Mississippi versus New York City (i.e. the setting of Liu's study). For example, household income in New York City is higher than Mississippi, and there is evidence that people with a higher household income are more likely to perceive higher levels of financial stress. Households with higher incomes have more access to numerous financial resources such as credit or loans and therefore more likely to have higher debt, leading to rising levels of perceived financial stresses Sweet et al. [31].

We also found women who reported high relational stress but low financial and trauma-related stress had the second highest likelihood of PPD indicating the significant role personal relationships play in the risk of PPD. Prior research suggests that the transition from childbirth to parenting is more challenging for couples who have some degree of conflict in their relationship, and women who do not have their partner's support during the postpartum period are more likely to develop PPD [10, 23]. High quality relationships may serve as a protective factor for women during pregnancy and improve their adjustment to other stressors. Banker [2] found that strong relationships and interpersonal support are protective against the effects of financial stress. However, our findings show that women with low relational stress but high financial and traumarelated stress also had a high likelihood of PPD, suggesting a supportive relationship alone may not be sufficient to protect against PPD in the setting of other significant stressors. Experiencing multiple stressors may alter the way individuals perceive the magnitude of stressors and have detrimental effects on their coping abilities [33].

This research presents new insight into the prevalence of stressful life events during pregnancy and PPD among women in Mississippi. The results provide public health professionals with valuable information about pregnant women who are at higher risk for PPD and highlight a need for prenatal screening for stressors, and the need for social and mental health support to combat PPD. A particular strength of this study is the use of a comprehensive approach for calculating life events stressors, looking at both the interaction between stressors and the degree of stress for a given cause. We believe it is important for providers to assess not only if a woman has PPD, but the potential coexisting stressors (financial, relational, emotional, trauma) as they may impact the needed interventions. The use of a population-based sample that is weighted to reflect the total birth population of Mississippi is another study strength.
The findings in this report are subject to several limitations. First, PRAMS is a cross-sectional questionnaire; therefore, causality and the direction of results cannot always be determined. Second, determination of PPD was based on the mother's self-report which may be subject to recall and social desirability biases. Third, the distribution of demographic characteristics of Mississippi PRAMS mothers suggests higher percentages of mothers with low income or only a high school education, and who are unmarried; as such, the findings may only be generalizable to other states with similar demographic characteristics. Fourth, 3 years of PRAMS data have been used in this study; multiple years of data should be concatenated in future research in order to achieve a larger sample size. Finally, this study may not measure all of the different factors that are associated with PPD. We did not examine the effects of pregnancy complications, and birth outcomes on PPD which should be considered in future research. In addition, PRAMS does not capture data on stress perception, past history of depression and biological factors, other types of stress such as those related to the father's support and adjustment which may affect PPD. These are complex emotional and personal experiences for which a questionnaire, at best can signal associations, but cannot provide a complete picture. However, on a population level, we believe PRAMS is a strong tool to guide surveillance and prompt further clinical investigation of PPD.

\section{Conclusion}

This study demonstrates that along with certain high risk demographics, the type, number and intensity of stressful experiences during pregnancy significantly impact the likelihood of developing PPD. The likelihood of PPD is particularly great among mothers reporting high levels of relational stress, demonstrating the importance of social support for pregnant and parenting women. Efforts to effectively prevent and manage PPD should focus not only on diagnosing and treating the clinical illness but should attempt to address and understand the potential sources of stress that can incite and exacerbate this condition for mothers.

Acknowledgments The researchers would like to thank all of the women who have responded to the 2009-2011 Mississippi PRAMS questionnaire. This study was made possible in part by Grant\# RFADP-11-001 from the Centers for Disease Control and Prevention.

\section{Compliance with Ethical Standards}

Conflict of interest None of the authors have any financial or other conflict of interests to disclose. 
Disclaimer The findings and conclusions described in this article are those of the authors and do not necessarily represent the official position of the Mississippi State Department of Health, the CDC, or any other organization.

\section{References}

1. Ahluwalia, I., Merritt, R., Beck, L., \& Rogers, M. (2001). Multiple lifestyle and psychosocial risks and delivery of small for gestational age infants. Obstetrics and Gynecology, 97, 649-656.

2. Banker, J. E. (2010). Understanding postpartum depression from a structural family theory perspective: Examining risk and protective factors. Retrieved from http://scholar.lib.vt.edu/theses/ available/etd-08272010-151832/unrestricted/Banker_JB_D__ 2010.pdf

3. Banker, J. E., \& LaCoursiere, D. Y. (2014). Postpartum depression: risks, protective factors, and the couple's relationship. Issues in Mental Health Nursing, 35(7), 503-508. doi:10.3109/ 01612840.2014 .888603

4. Boyce, P., \& Hickey, A. (2005). Psychosocial risk factors to major depression after childbirth. Social Psychiatry and Psychiatric Epidemiology, 2005(40), 605-612.

5. Brummelte, S., \& Galea, L. A. (2016). Postpartum depression: Etiology, treatment and consequences for maternal care. Hormones and Behavior, 77, 153-166. doi:10.1016/j.yhbeh.2015.08. 008

6. Burns, E. R., Farr, S. L., \& Howards, P. P. (2015). Stressful life events experienced by women in the year before their infants' births-United States, 2000-2010. MMWR, 64(09), 247-251.

7. Chojenta, C., Loxton, D., \& Lucke, J. (2012). How do previous mental health, social support, and stressful life events contribute to postnatal depression in a representative sample of Australian women? Journal of Midwifery \& Women's Health, 57(2), 145-150. doi:10.1111/j.1542-2011.2011.00140.x

8. Copen, C. E., Daniels, K., Vespa, J. \& Mosher, W. D. (2012). First marriages in the United States: Data from the 2006-2010 National Survey of Family Growth. In National health statistics reports; no 49. Hyattsville, MD: National Center for Health Statistics. 2012.

9. Demirchyan, A., Petrosyan, D., \& Armenian, H. K. (2014). Rate and predictors of postpartum depression in a 22-year follow-up of a cohort of earthquake survivors in Armenia. Archives of Women's Mental Health, 17(3), 229-237. doi:10.1007/s00737013-0404-5

10. Dennis, C., \& Ross, L. (2006). Women's perceptions of partner support and conflict in the development of postpartum depressive symptoms. Journal of Advanced Nursing, 56(6), 588-599.

11. Field, T. (2010). Postpartum depression effects on early interactions, parenting, and safety practices: A review. Infant Behavior \& Development, 33(1), 1-6. doi:10.1016/j.infbeh.2009.10.005

12. Gaynes, B. N., Gavin, N., Meltzer-Brody, S., Lohr, K. N., Swinson, T., Gartlehner, G., et al. (2005). Perinatal depression: prevalence, screening accuracy, and screening outcomes. Evidence Report Technology Assessment (Summ), 119, 1-8.

13. Hannaford, P. C., \& Owen-Smith, V. (1998). Using epidemiological data to guide clinical practice: Review of studies on cardiovascular disease and use of combined oral contraceptives. BMJ, 316, 984-987.

14. Hobel, C. J., Goldstein, A., \& Barrett, E. S. (2008). Pyschosocial stress and pregnancy outcome. Clinical Obstetrics and Gynecology, 51(2), 333-348. doi:10.1097/GRF.0b013e31816f2709

15. Horenstein, J., \& Cohen, S. (2008). Social support. In R. E. Ingram (Ed.), The international encyclopedia of depression (pp. 514-517). New York: Springer Publishing Company.
16. Lederberg-Stone, S., Diop, H., Declercq, E., Cabral, H. J., \& Wise, L. A. (2015). Stressful events during pregnancy and postpartum depressive symptoms. Journal of Women's Health (Larchmt), 24(5), 384-393. doi:10.1089/jwh.2014.4857

17. Lerman, R. I., \& Ooms, T. J. (2009). Young unwed fathers: Changing roles and emerging policies. Philadelphia: Temple University Press.

18. Lincoln, A., Feverharm, R., Damron, P., DeVault, M., Lorenz, D., \& Dooley, S. (2008). Maternal depression after delivery in Oklahoma. Journal of Oklahoma State Medical Association, 101, 307-311.

19. Liu, C. H., \& Tronick, E. (2013). Re-conceptualising prenatal life stressors in predicting post-partum depression: Cumulative-, specific-, and domain-specific approaches to calculating risk. Paediatric and Perinatal Epidemiology, 27, 481-490. doi:10. 1111/ppe. 12072

20. Lobel, M., Cannella, D. L., Graham, J. E., DeVincent, C., Schneider, J., \& Meyer, B. A. (2008). Pregnancy-specific stress, prenatal health behaviors, and birth outcomes. Health Psychology, 27(5), 604-615. doi:10.1037/a0013242

21. Meltzer-Brody, S. (2011). New insigths into perinatal depression: Pathogenesis and treatment during pregnancy and postpartum. Dialogues in Clinical Neuroscience, 13, 89-100.

22. Mollborn, S., \& Lovegrove, P. J. (2011). How teenage fathers matter for children: Evidence from the ECLS-B. Journal of Family Issues, 32(1), 3-30.

23. Montgomery, P., Bailey, P., Purdon, S. J., Snelling, S. J., \& Kauppi, C. (2009). Women with postpartum depression: "my husband" stories. BMC Nursing, 8, 8 .

24. Nkansah-Amankra, S., Luchok, K. J., Hussey, J. R., Watkins, K., \& Liu, X. (2010). Effects of maternal stress on low birth weight and preterm birth outcomes across neighborhoods of South Carolina, 2000-2003. Maternal and Child Health Journal, 14(2), 215-226. doi:10.1007/s10995-009-0447-4

25. O'Connor, A. M. (2013). Interpretation of odds and risk ratios. Journal of Veterinary Internal Medicine, 27, 600-603.

26. O'Hara, M. W., \& McCabe, J. E. (2013). Postpartum depression: Current status and future directions. Annual Review of Clinical Psychology, 9, 379-407. doi:10.1146/annurev-clinpsy-050212-185612

27. Rogers, C. E., Kidokoro, H., Wallendorf, M., \& Inder, T. E. (2013). Identifying mothers of very preterm infants at-risk for postpartum depression and anxiety before discharge. Journal of Perinatology, 33, 171-176. doi:10.1038/jp.2012.75

28. Rubertsson, C., Wickberg, B., Gustavsson, P., \& Rådestad, I. (2005). Depressive symptoms in early pregnancy, two months and one year postpartum-prevalence and psychosocial risk factors in a national Swedish sample. Archives of Women's Mental Health, 8, 97-104.

29. Seng, J. S., Sperlich, M., Low, L. K., Ronis, D. L., Muzik, M., \& Liberzon, I. (2013). Childhood abuse history, posttraumatic stress disorder, postpartum mental health, and bonding: A prospective cohort study. Journal of Midwifery Women's Health, 58(1), 57-68. doi:10.1111/j.1542-2011.2012.00237.x

30. Stuart, S. (2012). Interpersonal psychotherapy for postpartum depression. Clinical Psychology Psychotherapy, 19(2), 134-140. doi: $10.1002 / \mathrm{cpp} .1778$

31. Sweet, E., Nandi, A., Adam, E., \& McDade, T. (2013). The high price of debt: Household financial debt and its impact on mental and physical health. Social Science \& Medicine, 91, 94-100

32. Yim, I. S., Stapleton, L. R. T., Guardino, C. M., Hahn-Holbrook, J., \& Schetter, C. D. (2015). Biological and psychosocial predictors of postpartum depression: Systematic review and call for integration. Annual Review of Clinical Psychology, 11, 99-137. doi:10.1146/annurev-clinpsy-101414-020426

33. Zeidner, M. \& Endler, N. S. (1995). Handbook of coping: Theory, research, applications. John Wiley \& Sons, Inc. ISBN: 978-0471-59946-3 